\title{
Ant Address
}

ON

$$
\text { A P H A S I . }
$$

Read before the Birmingham Branch of the British Medical Association on November 15TH, 1910.

BY

ROBERT SAUNDBY, M.D., LL.D., F.R.C.P., SENIOR PHYSICIAN TO THE GENERAL HOSPITAL; PROFESSOR OF MEDICINE AT THE UNIVERBITY OF BIRMINGEAM; PREBIDENT-

ELECT OF THE BRITISH MEDICAL ABSOCIATION.

I HAVE had recently under my care two cases of aphasia which terminated after a few weeks' illness, and we were able to complete our notes by careful post mortem examinations. They illustrate the two principal clinical types of aphasia and the lesions associated with them, and way serve to introduce a discussion of the recent criticisms which have been directed against the doctrine of Broca.

These types are:

(1) Motor or Ataxic Aphasia, in which inability to speak is associated with paralysis of the right side of the body. This is generally held to be dependent upon a lesion of the third left frontal convolution or the fibres coming from it.

(2) Sensory or Amnesic Aphasia, in which the patient can speak although his vocabulary is limited, and he uses wrong words, but he can neither read nor write, although his eyesight is good and the movements of his hands are not affected. In this the lesion is localized in the neigh. bourhood of the first temporal sphenoidal convolution, the angular gyrus and the supramarginal convolution. The first case illustrates the former type.

CASE I.-Motor Aphasia.

J. M., coachman, aged 64 , was admitted to the General Hospital on February 17th, 1910, with a history that three days before he had suddenly lost his speech; he was at dinner, and when his wife spoke to him he could not answer her; he wanted to return to work, and was annoyed when she stopped him. There was no convalsion, or any sign of paralysis or loss of consciousness. When admitted he was quite unable to speak, and could make only inarticulate noises when pressed, but he seemed to understand all that was said to him, and was able to read and write. He could do a simple addition sum, but when set an equally simple sum in division he failed. There was slight flattening of the lower part of the right side of the face, and the tongue deviated towards the right side, but there was no weakness of the right arm or leg; the knee-jerks were normal no weakness of the right arm or leg; the knee-jerks werenormal
on both sides, and the plantar reflexes were flexor. His pulse was 56, blood pressure 120; the artery felt thickened; the heart was not enlarged, its sounds were normal; the urine was free from albumen.

On February 23rd some weakness of the right hand was noticed, and later on he lost the power of writing, became dazed and stupid, and by midday he could not be roused to take his food. The right side of the face was paralysed, and tberight arm and leg were motionless and slightly stiff. The right plantar reflex had become extensor, and the leg was not drawn up, while on the left side it was flexor, and the leg was drawn up briskly. He lay in this condition for three or four deys, but on the 27th he improved, and showed response when spoken to, but could not speak, and the right arm and leg were completely paralysed. On February 28th he was found to have lost the power of reading, and the attempt to write his name with his power of reading, and the attempt to write his name with his without any change, but on March 17th there was a sudden rise of temperature, reaching on the following day to $102.8^{\circ}$, and after that his temperature remained irregular until he died on March 3lst.

Necropsy.

The post-mortem examination was performed by Dr. Douglas, aum pory of whose report is as follows:

The body was thin and wasted; both lungs showed considerable emphysema, and the lower hall of the right lung was hepatized. The right ventricle of the heart was dilated, and the radial arteries were thickened. There was some fibrosis present in both kidneys.

Brain.-There was no external change visible in the brain. On section the softened area was found lying internal to the grey matter of the island of Reil on the left side. Portions of the deep-lying nuclei were completely macerated. The anterior part of the thalamus and the internal capsule seemed to be of normal consistence, but the posterior external part of the thalamns, and that part of the corona radiata entering the posterior portion of the internal capsule and a small portion of the capsule itself were softened. The posterior part of the nucleus caudatus was softened. Of the lenticular nucleus, the putamen was entirely destroyed, except for a small portion occupying its antero-inferior aspect, while the globus pallidns wes normal. The posterior two-thirds of the external capsnle and the claustrum were softened. The grey matter of the island of Reil was intact except a minute prey matter of the island of Reil was intact the posterior extremity, but the posterior half of the portion at the posterior extremity, but the posterior half of the White matter, between the grey matter of the convolutions and the claustrum, was softened. No blocked vessel was seen, but the arteries at the base of the brain were thickened, and showed convolution was quite normal.

This is a case of pure motor aphasia, in which the patient could do everything but speak : he could bear and understand all that was said to him; he could read and write, and, although his power of calculating was not very good, it is not possible to say that this was the result of the brain condition that had supervened. This is the type of aphasia which Professor Wyllie has called infrapictorial motor aphasia, due, in his opinion, to a $\mathrm{kub}$. cortical lesion, which cuts across the fibres running through Broca's convolution and also that coming from the right hemisphere, termed the "callosal speech tract." He says it would appear that a lesion in the upper and anterior part of the island of Reil máy, by penetrating into the subadjacent white matter, cut them both across, and so produce the infrapictorial variety of motor aphasia, and this, in fact, was what was found at the post-mortem examination. It is difficult to see wby a lesion which severs the fibres before they reach the internal capsule should be capable of producing aphasia, but after they have combined together and form part of that band of have combined not do so. Professor Wyllie says that below the upper part of the internal capsule the direct fibres from Broca's convolution on the left side and the callosal fibres from the right side diverge from each other after entering the internal capsule, and are less and less likely to be cut across by the same lesion until they come near each other again in the pons, and therefore lesions at and below the upper part of the internal capsule usually produce merely a dysarthria or diffioulty of articulation, and not an aphasia of the infrapictorial motor type. This explanstion may satisfy those who believe that the Innction of the third left frontal convolution has been established and are ready to accept any excuse for those awkward facts which do not conform to this view.

\section{Case II.-Sensory Aphasia.}

B brass-caster aged 35, was admitted to the General Hospital on March 16th, 1910, with a history that three weeks before admission, while at his work, he was taken with sudden giddiness, temporary loss of sight, and severe headache. He stayed at home for three days, and then went back to try to do his work, but was unable to do it, and had been at home since. After his attack there was numbness and weakness in the right arter his attack the to a less extent in the left hand. His speech arm and hand, and to a less extent in the left hand was nnaffected, but he was irritable, and complained of constant headache. Three days before his admission he seemed worse; he forgot words, and was unintelligible. The weakness of the right arm and leg increased, so that he dragged his right leg. His memory was was said to him. He was drowsy by day and sleepless by night.

On admission he was a well-developed man of healthy and On admission he was a well-developed man of fattened, and intelligent aspect. The right side of the face was fatened, and the tongue devisted to the right. The right arm was weak, bus could be moved freely, and the right leg was dragged a little in walking. The right knee-jerk was increased, and the plantar reflex was extensor; the organic reflexes were normal. The movements of the eyeballs, the pupils, and ophthalmoscopio appearances were all normal

ver the right trigeminal area.

The Aphasia.- The patient could say short sentences, pronouncing his words perfectly well ; for example, when he was asked how he wss, he said, "All right." Asked if he had any pain, he said, "In my hesd," but he conld not tell his own or his wife's name, yet he said quite distinctly, "I do not know now." He could not tell the day he had been accustomed to get his pay, nor his age, but when 35 was s"ggested to him get his pay, nor hreed. Asked to repest his name, he said, "I cannot." Asked why, he said, "It is a funny thing, sin't it?" but Asked why, he said, It is a funny thing, same, but had after pressing a little be repeated his name, but had forgotten it immediately afterwards. He was unable to read even large letters in a spelling book or to write his name or copy words, but he could point out objects named to him, and recognize their uses when they were shown to him, though he could not tell their names, and seemed unable to repest their nemes when they were told to him. He seemed worried by his insbility, and evidently tried hard to do what he was asked, but complained that the effort made his head ache. On the but complained that the effort made his head ache. On the 24th he is reported to have become excited and incoherent, and on the $28 \mathrm{th}$ his mental power was evidently failing. He did not seem able to understand what was said to him, and when [2620] 
seem in the least aware of the incongruity of the remark. On April lst he was in a drowsy condition, which by the 3rd had deepened into coma, which was followed by death on that day.

Necropsy.

The post-mortem examination was performed by Dr. Douglas, whose report I summarize briefly here, omitting, as there is nothing important in them, the descriptions of all the organs except the brain.

Brain.-Meninges were normal, and there was no optic neuritis to be seen in the left disc. A large tumour occupied considerable proportion of the left cerebral hemisphere meanning 21 in. from before backwards, 2 in. from side to side, and 2 in. from above downwards. It involved the ascending parietal angular and supramarginal convolutions, these being much distorted and stretched by it. Its front part was degenerated into a large cyst, but behind it was solid, its lower part being haemorrhagic and dark red, and the upper a pale pinkishwhite. It extended anteriorly as far as the fissures of Rolando below it reached the lower border of the second temporal gyrus. It lay external to the lateral ventricle, being situated in the white matter of the parietal lobe. The grey matter at the lower extremity of the anterior limb of the supramarginal gyrus was much eroded.

The lesion here corresponds with the descriptions which have been for many years accepted. The tumour involved the ascending parietal, the angular and supramarginal convolutions, especially the angular gyrus, which is the visual centre that has been found to be affected in cases of word blindness. The patient was an intelligent man of fair education, but he was quite unable to read or recog nize even the letters of the alphabet in a spelling book. Moreover, although there was no true paralysis, he could not write his name or copy words that were given to him, so that the graphic centre, which is probably closely related to the visual contre, was also affected Writing, like drawing, depends upon the exercise of visual memory or the memory of form, and although this might be supposed not to apply to copying, yet we know it is by no means easy to induce a child to copy letters set before it, and our patient may be regarded as reduced to the level of a perfectly uneducated person who is asked to copy handwriting.

It is usually said that auditory memory is situated in the first temporo-sphenoidal convolution, but the patient heard and understood perfectly well all that was said to him. The characteristic of the case was the fact that although the patient could speak he talked nonsense, and was unable without great effort to repeat words when asked to do so as, for example, to repeat his own name; yet what he said was clearly articulated and properly pronounced. This remarkable condition was due to the loss of memory of the greater part of his vocabulary from destruction of the centres concerned in originating the impulses for speech production. When a normal individual is asked to repeat a word this may be accomplished with more or less effort, which is great in proportion to the strangeness of the word, and by practice becomes easy and antomatic, but where the centres concerned are damaged or destroyed it is difficult or impossible.

The association of motor aphasia with a lesion of the third left frontal convolution is called Broca's doctrine, and has been for the last thirty or forty years generally accepted by the medical profession, but a powerful protest has been in these later years made against it by Professor Pierre Marie.

Let me relate briefly the circumstances under which Broce announced his discovery: In 1808 appeared the work of Gall and Spurzheim on phrenology or the localization of the mental faculties in the brain; and in subsequent writings appearing between 1810 and 1822 Gall localized the centres of language in the supraorbital lobes of the brain. According to his view, the development of this region tends to depress the ejes and make them prominent, so as to cause distension of the lower eyelids, and it is said, although this may not be true, that Gall had been led to this opinion by the garrulity of one of his schoolfellows who had this defect. However derived, the doctrine of the localization of the faculty of language in the anterior lobes of the brain was adopted and supported by Professor Bouilland in a series of memoirs produced at the Academy of Medicine in Paris. The first was read in 1825, and was entitled "Clinical Researches to demonstrate that the Loss of Language corresponds to a Lesion of the Lobules of the Brain, and to confirm the opinion of Gall on the seat of the organ of articulated language." In this paper he maintained the existence of a special distinct and independent centre in the brain for the movements of the organs of speech, and he locelized it in the anterior "lobules." He distinguished loss of the faculty of speech from that of the movements of the tongue and lips.

These doctrines did not pass without criticism from such eminent persons as Cuvier, Flourens, and Gratiolet. Andral in his clinical lectures, published in 1834, drew attention to the coincidence of affections of speech with right-sided hemiplegia, and localized the lesion in the left corpus striatum and attacked Bouilland's doctrine. He had collected altogether 37 cases of various lesions of the anterior lobes of the brain, of which 16 showed no disturbance of speech, while, on the other hand, 14 cases of disturbance of speech were without alteration in this region. From time to time Bouilland retarned to his subject, and his persistence, joined to his great anthority as a physician, as a clinical teacher, and as Dean of the Faculty of Medicine, invested his views with no mean authority. In 1861 Broca was Secretary of the Society of Anthropology and surgeon to Bicêtre. Bouillaud in 1848 had offered a prize of 500 francs to any one who would produce a single case of an individual who had lost his speech without presenting a lesion of the anterior lobes of the brain, and this prize had never been claimed. In April, 1861, Broca having received at Bicêtre the patient Leborgne, asked Auburtin, Bouilland's son-in-law, to examine him, and shortly after was able to present to the Society of Anthropology notes of the case and the brain. This showed considerable softening of the anterior lobe of the left hemisphere, but the lesion was extensive. He spoke of the loss of language as "aphemia," and de fined it as a condition in which, while " the general faculty of language persists unaltered, where hearing is intact, where all the muscles except those of the voice and articulation obey the will, articulate language is abolished in consequence of a lesion of the brain." "All that is wanting in these patients is the faculty of articulating words." "They understand all that is said to them; they are intelligent, they can emit vocal sounds with facility, and execute with their tongue and lips all the movements which are required for the articulation of sounds, and yet they are unable to express themselves in language beyond, perhaps, a short series of syllables or a monosyllable." He goes on to say that the seat of the lesion was in the second or third frontal convolution, most probably in the last; it is therefore possible that the seat of articulate language is in one or other of these convolutions.

Shortly after this Brosa had an opportanity of making a post-mortem examination upon another aphasic patient and, "to his astonishment, he says the lesion "occupied rigorously" the same seat as in the first case, and he regarded this coincidence as confirming the seat of the lesion. In 1863 Parrot showed the brain from a case in which there was complete atrophy of the right island of Reil and of the third right frontal convolution, with com. plete preservation of intelligence and the faculty of language; a case which led Broca to modify his views so far as to restrict the localization to the left side of the brain. By 1865 Broca had come to regard his doctrine as a dogma which could not be dispated, but he availed himself of the suggestion that in a certain number of exceptional persons the faculty of language was seated in the third right frontal convolution, in order to explain such an observation as that of Morean of Tours, who was able to show the brain of a woman aged 47 who had never presented the slightest trace of aphasia, in spite of the extensive destruction of the third left frontal convolution

Left-handedness and the power of the opposite hemisphere to become educated to supply the place of the damaged left centre sufficed to explain all the contradictory cases published from time to time, and in spite of abundant evidence of the existence of lesions of the third left frontal convolution without affection of speech the doctrine became accepted by Troussean and Charcot in France, by Hughlings Jackson, Bastian, and Broadbent in England, and by Seguin in America; it was introduced into all textbooks, and has existed triumphantly to the present day. The other main fact to be remembered in the history of aphasia is that in 1874 Wernicke drew attention to a type of aphasia differing from that of Broca, in which the patient retains the power of speaking, although he has lost to a considerable extent the memory 
of words, his conversation is incoherent, and of the kind which has been called jargon-aphasia. The lesion in these cases was localized by Wernicke in the first left temporal convolution, and this doctrine has, with the inclusion of the supramarginal gyrus and the angular gyrus, held its ground. This area of the brain is the seat of the cortical centres for visual and auditory memory. Wernicke's paper led to the separation, now generally recognized, of aphasia into two types, ataxic or motor and amnesic or sensory aphasia, the orthodox view being that the former is localized in the third left frontal convolution, and the latter in the first temporo-sphenoidal, the supramarginal and angular gyrus of the left hemisphere.

Ataxic aphasia is met with clinically most commonly in association with right-sided hemiplegia, and the condition of the patient is usually unfavourable to any careful or detailed investigation of his mental condition. The paralysis of the right arm makes it impossible for him to write, and his power of communicating by gesture is limited, but it is admitted that in most of these cases there is some mental defect, and that they are not simply cases of loss of power of speech, all other functions of the brain being intact. Most of the cases of aphasia in which a lesion of the third left frontal convolution has been observed have been ceused by embolic plugging of the left middle cerebral artery at such a point that not only Broca's convolution but a considerable part of the brain is involved.

The extensive character of the lesions and the com. plexity of the symptoms have made it difficult to test the truth of Broca's dootrine. But the doctrine was assisted by the experiments of Fitz and Hitzig, Ferrier and Yeo, Horsley and Schaefer, who place the centres for the movements of the lips, mouth, and tongue in this region of the brain; these discoveries caused Charcot to overlook the cases he had reported in opposition to Broca and to accept the now popular opinion.

There is no doubt that the almost universal acceptance of Broca's view was due to its fitting in with the then prevalent philosophy; opposing facts were passed over, and even such a sound observer as Hilton Fagge explained those where "the third left frontal convolution may fail to present any obvious morbid change" as being due to some "unrecognizable interference with the blood supply." Broadbent ${ }^{1}$ and Fagge were such stout supporters of Broca's theory that after Wernicke's paper appeared they would not admit any other form of aphasia than that connected with the third left frontal convolution. We are generally told that the explanation of the associa. tion of right-sided hemiplegia with aphasia is due to the fact that the left side of the brain is the more educated, or, to use Hughlings Jacke on's picturesque expression, "the left side of the brain is the elder brother." The main argument for this is that in left-handed people, in whom we may believe that the right side of the brain takes precedence, left-sided hemiplegia is associated with aphasia. A good example was published by Dr. Wadham in the St. George's Hospital Reports for 1869. The boy was ambidextrous, but there was a good deal of evidence that he was really left-handed, and that his ambidexterity resulted from his having taught himself to use his right hand later. 'This boy could not speak, but could write and spell correctly; he was re-educated to speak to a certain extent, and then died. At the post.mortem ex. amination both third frontal convolutions were healthy, but the right island of Reil was destroyed.

Professor Marie is the Director of the great asylum of Bicêtre in Paris, which is for male patients what the Salpêtrière, where Charcot made his reputation, is for women. He has occupied this position for ten years, after having been Charcot's principal assistant at the Salpêtrière, and he is probably well known to most of us as the discoverer and describer of acromegaly and of the allied condition, osteo-pulmonary arthropathy. At Bicêtre he bas stadied no fewer than 100 cases of aphasia, of which he has been able to follow 50 to the post-mortent room, so that he speaks on no narrow basis of facts.

Professor Marie's view is that Wernicke's aphasia or sensory aphasia is the only true aphasia; that the loss of speech associated with right-sided hemiplegia should be called anarthria, and is a true motor paralysis which has nothing whatever to do with Broca's convolution. He localizes it in the part of the brain which is bounded extermally by the convolutions of the island of Reil, internally by the lateral ventricle, and anteriorly and posteriorly by lines drawn at right angles to the extremities of the convolutions of the island of Reil. When the lesion is limited to this space it causes only anarthria, where it extends further forward it produces no known extension of the symptoms, but if it extends backward it involves those intellectual centres a lesion of which causes sensory aphasia; under these conditions a mixed affection results, that is to say, anarthria plus more or less sensory aphasia, and it is to this type that most of the cases of Broca's aphasia belong. Professor Marie would therefore describe three conditions: (1) Pure anarthria, (2) anarthria plus a certain amount of aphasia, and (3) true aphasia or sensory aphasia.

Under the auspices of Professor Marie, Dr. Montier has published (L'Aphasie de Broca, Paris, 1908) \& complete account of the whole literature of aphasia, giving an analysis of all the cases that have been recorded. From these he has collected 27 examples in which the third left frontal convolution was alone involved, but in which no aphasia occurred; of these, 4 were tranmatic, 2 were surgical resections, 14 were tumours, 5 softenings, and in 2 there was bilateral softening of both third frontal convolutions. The two cases in which there was destruction of both third frontal convolutions seem to me to be absolutely incon. sistent with the orthodox doctrine of localization. They cannot be explained by any supposed right-handedness or supplementary education, and are therefore worth quoting briefly.

The first, published by Echeverria, was an epileptic aged 67, who was able to speak up to his death, although there was from time to time transitory trouble in his speech. At the autopsy both third frontal convolutions were atrophied.

The other was a case published by Comte in 1900: The patient was a working jeweller, aged 51, who at the age of 31 had an epileptiform attack, which was followed by transitory right-sided hemiplegia with aphasia. The hemiplegia disappeared but the difficulty of speaking remained. He spoke.continuously, but he presented disorder in the articulation of his words, in deglutition, and in mastication from sligh paralysis of the masticating muscles of the lips and tongue, such as are generally called pseudo-bulbar symptoms. At the post-mortem examination, on the laft side of the brain there was atrophy and sclerosis from chronic encephalitis of the whole of the third frontal, of the lower half of the ascending frontal and ascending parieta] convolutions, and of the first temporosphenoidal. On the right side there was atrophy of the foot of the third frontal, of the lower half of the ascending frontal, and of the ascending parietal.

The surgical resections were two cases presented by Burckhardt to the International Congress at Berlin in 1890 , and are to be found in the Transactions of the Congress, and also in the Zeitschrift für Psychologie, 1891, p. 463. In both cases the third left frontal convolution was excised in the hope of removing or diminishing verbal hallucinations from which the patients, who were lunatics, were suffering. In neither case did motor aphasia result.

1 The first patient was a young painter, right-handed, aged 26 , who suffered from anditory hallucinations, and the operator who sufer that the centres of language of Wernicke and suggested that the centres of language of Werion he removed Broca might be excised. At the first operation he remove the posterior part of the first and second left temporoand the anditory hallacinations diminished. There was no trace of verbal deafness. Some days afterwards there was slight hesitation in speaking, but this disappeared. The following year there seemed to be a relapse in his condifolowing Bearhardt resected the third left frontal. As the tion, 8o Burkhardt resected the chloroform he said, "Listen"; patient was coming out of the chloroform

at no time did he show any ataxic aphasia. right-handed; the The other case was a woman aged 51, right-handed; the operation was performed for a similar condition. At the first opran incomplete hemiplegia in the left side. In the second operation the lower part of the first and second left temporo-sphenoidal the lower part of hemoved. Two months afterwards the third convolutions were removed. Two months afterwardse superior operstion was performed, and he removed part of the superior parietal, the supramarginal gyrus, and the angular gyrus. There was no interference with speech after this operation. The patient was constantly talking. At the fourth operation he removed the third left frontal convolution; she recovered anguage.

A remarkable case, published by Professor Pierre Marie 
and Dr. Moutier, is that of an old man aged 64, who died at Bicêtre under their care.

He had been admitted for mitral disease and bronchitis, and there can be no doubt that language was quite unaffected. Moreover, he had always been right-handed. He died on December 11th, 1906; on the 2nd of that month he complained of a little numbness and weakness of the right hand, but there was no hemiplegia nor any Babinski's sign. There had been nothing to attract attention to the brain, which was only being examined in accordance with their rule of making a thorough antopsy of all cases, and this is what they found: In the left hemisphere the foot of the third frontal convolution was very distinctly atrophied in comparison with the foot of the right third frontal. Moreover, a "worm-eaten" patch had destroyed the grey matter of the upper half of the posterior branch of the cap and of the superior third of the foot of the third left Irontal.

The published photograph ${ }^{8}$ shows better than any description the extent of the lesion, and is almost an exact copy of the lesion shown in the plate published by Take and Fraser ${ }^{2}$ in the account of their case. It differs from Take and Fraser's case in there never having been any disturbance of the faculty of language.

It is difficalt to see how it is possible to escape from the amount of evidence brought forward to show that destruction of the third frontal convolution, even on both sides, does not cause aphasia; bat almcst equally cogent, and even more abundant, is the evidence that aphasia occurs in cases where this convolution is intact. The usual answer in this evidence is that while it may appear intact, it is not so really; but Professor Marie has lately pub. lished three cases of this kind in which the convolution was examined microscopically by serial sections without any lesion being discovered. The only rejoinder that the supporter of Broca can make is that the lesion is functional in character, and reveals itself by no changes which can be detected by our present mosns of research. Bat those who make this assertion must bear the onus of proof, and it is not easy to produce evidence in its favour. If the convolation of Broca is the seat of the faculty of language its destraction should be invariably followed by loss or impairment of that faculty; farther, when there is loss or impairment of the faculty of language $t$ jis convolu. tion should show always some demonstrable change; if neither of these relations exist, then the only possible verdict must be that the existence of the supposed relation is not proved.

REFERENCES.

1 Britrsh Medical Jodrnat, 1876, vol. i, p. 433. 2 Journal of Mental Science, vol. xviii, p. 46 . 8 L'Aphasie, p. 397.

\section{TWO CASES OF HEREDITARY CONGENITAL WORD-BLINDNESS.}

\section{BY}

JAMES HINSHELWOOD, M.A., M.D.,

SORGEON TO GLASGOW EYE INFIRMARY AND LECTURER ON OPHTHALMOLOGY IN THE GLASGOW WESTERN MEDICAL BCHOOL.

Ar the Exeter meeting of the British Melical Association in 1907 I read a paper ${ }^{1}$ in the Section of Ophthalmology on four cases of congenital word-blindness occurring in the same family. Dr. C. T. Thomas ${ }^{2}$ in a paper in the Ophthalmic Review, in August, 1905, had already called special att intion to the fact that congenital word-blindness may assume a family type and that a hereditary tendency is probable. I recorded the four cases in one family as a confirmation of the correctness of this observation. The two cases I am about to record are a still farther confirma. tion of the hereditary tendency, as they occur in the second generation of the same family which afforded the subjects of my communication to the British Mediosl Association in 1907.

The four cases previously reported were the youngest members of the family. The two cases in the present paper are the children of the oldest daughter of the same family, and hence are the nephew and niece of the cases previously reported. The mother of these two children never herselt experienced any difficulty in lesrning to read. She has six children and the other four members of the family have learnt to read without any special difficulty.
A., a girl 12 years of age, has been at school for seven years. She has experienced the greatest difficulty in learning to read, and at present cen only resd very imperfectly, being able to recognize by sight only some of the commonest monosyllabic words. For several years she seemed to make vary little progress, but has done much better during the last year. She progress, but has done much better during the last year. She in learning them. She can recognize by sight most of the common words of one syllable, snch as the, of, in, are, which, to, with, and so on, but most of the rarer monosyllabic words she cannot recognize by sight alone, although she recognizes them nearly all at once when spelt out aloud to her. She recognizes by sight scarcely any words of more than one spllable, but many of these she also recognizes, if they are spelt out aloud to her. She has never had the slightest difficulty with arithmetic, and in fact has been rather good at it and above the average. She is at present in the compound rules, and has no difficulty in keeping up with the rest of the class in this subject. Bhe has no difficulty in committing things to memory, and seems a sharp, intelligent girl in every other respect.

D. is a boy aged 10 years, and has been at school for four years. He has made very little progress in learning to read by sight. He does not know. by sight all the letters of the alphabet, although he can repest them correctly in sequence. He can scarcely recognize any words by sight. Out of a whole page of a child's primer he recognized by sight only two words, to and go. When I spelt the words out aloud to him and appealed to his auditory memory he recognized every word on the page. He can spell nearly all the small words, and can recognize them when they are spelt aloud to him, but he canno recognize them br the sense of sight alone. Whilst the visual memory for words is so defective the auditory memory seems good. He has therefore experienced no difflculty in committing things to memory which have been read aloud to him, such as pieces of poetry. With regard to arithmetic he has had the same difficulty as with regard to reading. He can repeat the figures in sequence up to "100," and can write them also. But if the figures are written down separately he can only recognize them with certainty up to " 20 ," and very few combinations after that.

In other respects than learning to read and count, he seems quite a smart intelligent boy.

The first case, that of the girl, does not call for any very special remark. It is a typical case of abnormal difficulty in registering in the brain the visual symbols of letters and worde. The degree of difficalty in this case, however, has not been nearly so great as is met with in many cases. The difficulty, of course, varies greatly in degree, some cases being comparatively mild, and others where the difficulty is so great as to seem at first insuperable. The girl's case is a mild case, because she has now, after seven years of teaching in the ordinary way, acquired the visual memories of the most common monosyllabic words. I have seen and recorded c 380 s where, after seven years of ordinary training, the child had practically acquired nothing so far as the visual memory of words and letters is concerned. The case of the girl may be regarded as a mild case of congenital word-blindness, and if now taught in the proper way, I am certain will soon be able to read quite well.

The second case, that of the boy, is of a much more severe type. Here the difficulty has been much greater than in the case of the girl, as, after four years' similar training, he has acquired scarcely any visual memories of words or letters, not even recognizing by sight all the letters of the alphabet. An important point in his case is that he has experienced the same difficulty in dealing with figures. This is in contrast to his sister, and also in contrast to the four cases which I reported in 1907, none of whom experienced any difficalty with arithmetic and some of whom were above the average at it. When this difference exists, it is helpfal in the diagnosis.

In $m y$ book $^{8}$ on letter, word, and mind blindness I have shown from the stady of cases of acquired word-blindness that the visual memory for words and letter $s$ is completely independent of that for figures, and hence in congenital word.blindness it is not surprising that whilst the visual memory for words may be very defective, that for numbers may be perfectly normal.

In my last paper ${ }^{1}$ I remarked, in discussing this subject, that too much importance in the diagnosis should not be assigned to the relative difference in acquiring the visual memories of words and figures, as cases had been reported where the difficulty extended to both figures and words. The case now under consideration affords confirmation of this observation. It is a typical case of congenital wordblindness, where the difficulty also extends in equal degree to figures. Nor should the occasional occurrence of this 